\title{
A Novel Double-Piston Magnetorheological Damper for Space Truss Structures Vibration Suppression
}

\author{
Qiang Wang, ${ }^{1}$ Mehdi Ahmadian, ${ }^{2}$ and Zhaobo Chen ${ }^{1}$ \\ ${ }^{1}$ School of Mechatronics Engineering, Harbin Institute of Technology, Harbin 150001, China \\ ${ }^{2}$ Department of Mechanical Engineering, Center for Vehicle Systems and Safety, Virginia Polytechnic Institute and State University, \\ Blacksburg, VA 24061, USA \\ Correspondence should be addressed to Qiang Wang; qiangwang1985@gmail.com
}

Received 10 March 2014; Revised 30 June 2014; Accepted 30 June 2014; Published 22 July 2014

Academic Editor: Nuno Maia

Copyright (C) 2014 Qiang Wang et al. This is an open access article distributed under the Creative Commons Attribution License, which permits unrestricted use, distribution, and reproduction in any medium, provided the original work is properly cited.

\begin{abstract}
The design, fabrication, and testing of a new double-piston MR damper for space applications are discussed. The design concept for the damper is described in detail. The electromagnetic analysis of the design and the fabrication of the MR damper are also presented. The design analysis shows that the damper meets the weight and size requirements for being included in a space truss structure. The prototype design is tested in a damper dynamometer. The test results show that the damper can provide nearly $80 \mathrm{~N}$ of damping force at its maximum velocity and current. The test results also show that the seal drag could contribute significantly to the damping forces. Additionally, the test results indicate that both the work by the damper and damping force increase rapidly with increasing current at lower currents and taper off at higher currents as the damper starts to saturate. The damper force versus velocity plots show hysteresis in both pre- and postyield regions and asymmetric forces in jounce and rebound. A model is proposed for representing the force-displacement, force-velocity, and asymmetric forces observed in test results. A comparison of the modeling results and test data indicates that the model accurately represents the force characteristics of the damper.
\end{abstract}

\section{Introduction}

This paper will address the application of magnetorheological (MR) dampers for space structures, such as a truss structure that can be folded on the ground and deployed in space. MR dampers use magnetorheological fluids that are able to change their rheological properties in the presence of a magnetic field. MR fluids have been suggested for a wide variety of applications. Among them, MR dampers (or shock absorbers) have proven to have the widest range of applications, with the highest potential for commercialization. Some of the performance advantages of MR dampers include continuously controllable force, high dynamic bandwidth (rapid transition from one state to another), and low power consumption. Because of these advantages, MR dampers have been evaluated for a wide variety of applications such as commercial vehicle suspension systems [1-4], railway vehicles suspensions [5, 6], aircraft landing gears [7-9], helicopter lead-lag dampers [10-13], operator seat suspensions $[14,15]$, seismic mitigation of buildings and bridges [16-20], and gun recoil control [21-23].

Past studies have shown that MR fluid can be used in any of the distinct dynamic modes shown in Figure 1:

(i) valve or (flow) mode (Figure 1(a)),

(ii) shear mode (Figure 1(b)),

(iii) squeeze mode (Figure 1(c)).

It is also possible to use the fluid such that two of above modes are combined. For instance, combining the valve mode and shear mode in a damper results in the arrangement illustrated in Figure 1(d). The most commonly used ones are the valve mode and valve and shear mode.

The majority of the available MR dampers are based on a design that applies the fluid in one of the modes in Figure 1. As is shown schematically in Figure 2, the dampers can be single- or double-ended and include either an internal or external fluid passage that incorporates the electromagnet 


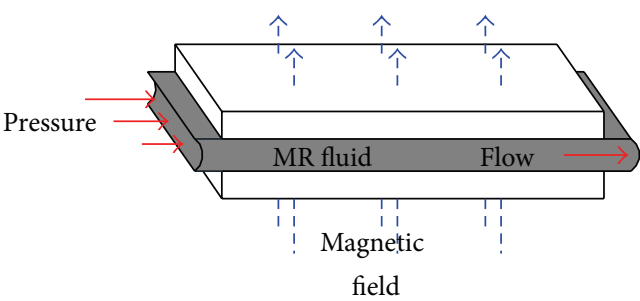

(a)

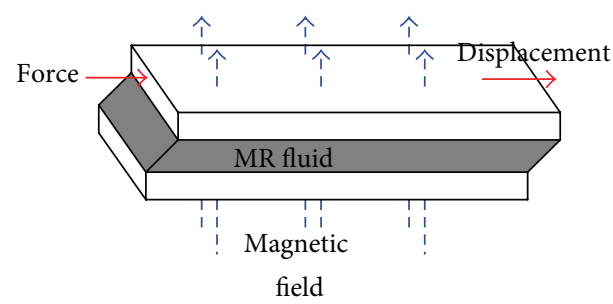

(b)

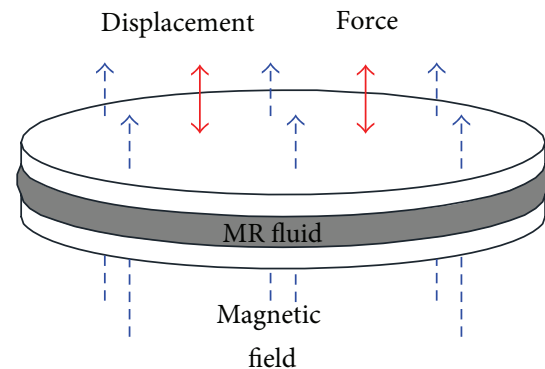

(c)

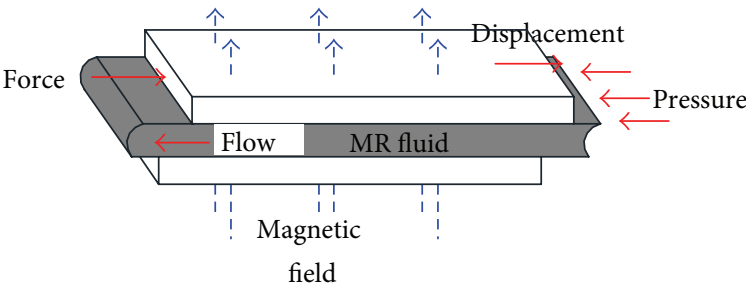

(d)

FIgURE 1: MR fluid flow modes: (a) valve mode, (b) shear mode, (c) squeeze mode, and (d) valve and shear mode.

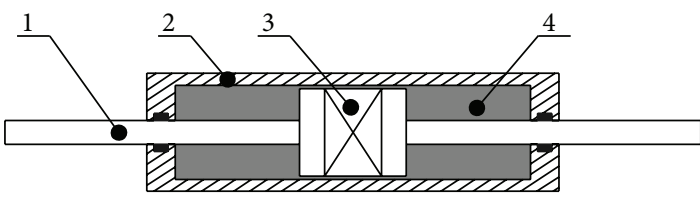

(a)

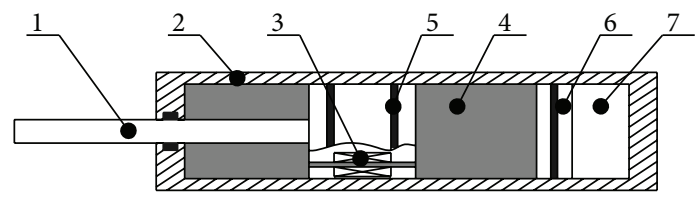
(1) Piston rod
(5) Piston seal
(2) Cylinder
(3) Coil
(6) Floating piston
(4) MR fluid
(8) Piston guide

(c)

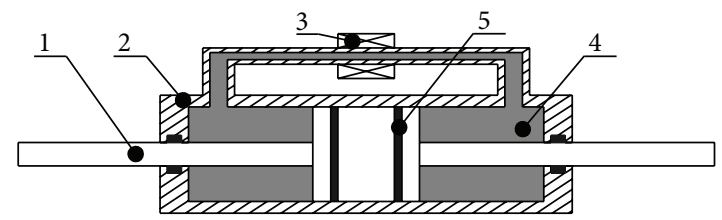

(b)

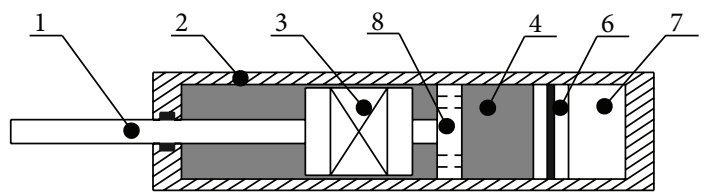

(5) Piston seal

(6) Floating piston

(7) Accumulator

(8) Piston guide

(d)

FIGURE 2: Available MR dampers designs: (a) a double-ended valve and shear mode one, (b) a double-ended bypass valve mode one, (c) a single-ended valve mode one, and (d) a single-ended valve and shear mode one.

needed for changing the fluid's flow properties. Past studies have considered various configurations shown in Figure 2, including a double-ended damper in valve and shear mode $[6,18,21]$, a double-ended damper in valve mode with bypass valve $[19,20]$, a single-ended damper in valve mode $[1,3-5,7-$ $9,12,15-17]$, and a single-ended damper in valve and shear mode $[2,22,23]$.

Figure 2(a) shows a double-ended valve and shear mode MR damper. The coil is included within the damper piston that moves relative to the damper body. The coil leads pass through the piston rod and are connected to the electrical power supply that is commonly placed outside of the damper.
The magnetic flux generated by the electrical coil passes through the damper body and the fluid that is captured in the small gap between the body and piston, closing the magnetic field around the piston. This results in subjecting the MR fluid to a magnetic field with a flux density proportional to the current passing through the coil. The fluid flow is perpendicular to the magnetic field passing through the fluid. MR fluid in this damper works in a combination of valve mode and shear mode. Because the rod volume within the damper body remains unchanged, a double-ended damper has a constant fluid chamber volume. This is in contrast to a single-ended damper that has a variable fluid chamber 
volume, depending on how far the damper rod is inserted inside the chamber. In such cases, a floating piston or a twintube design is used to accommodate the change in the fluid chamber volume while keeping it fully filled with MR fluid.

Figure 2(b) shows a double-ended valve mode MR damper with an external fluid passage, to accommodate the flow between the chambers on the two sides of the piston. The external tube enables incorporating an electrical coil for passing a magnetic field through the MR fluid, as it flows within the tube. The fluid flow inside the passage is perpendicular to the magnetic field, subjecting the $M R$ damper to valve mode. In this design, there is no gap between the piston and damper cylinder, and as such the fluid passes through a passage that is incorporated within the piston. A band seal with low coefficient of friction (commonly made of Teflon material) is used to prevent any fluid leakage around the piston. Since the magnetic field does not pass through the damper body, it can be made of nonmagnetic materials. The external coil can provide a better dissipation of the heat generated by the electrical coil. A disadvantage of this design is the space needed for accommodating the external passageway.

Figure 2(c) shows a single-ended valve mode MR damper, where the MR fluid flow orifice is directly on the damper piston. The coil is integrated inside of the piston. The damper design is similar to the double-ended one in Figure 2(b), except that an accumulator is needed to compensate the change in fluid chamber volume caused by the varying rod volume that must be accommodated as the piston moves relative to the damper body. A high-pressure gas chamber, separated from the fluid chamber by a floating piston, is incorporated in series with the fluid chamber to enable varying the latter without causing any vacuum. The damping force reduces significantly if the damper cavitates due to the lowering of the boiling pressure of the fluid in vacuum.

The final arrangement shown in Figure 2(d) is a singleended valve and shear mode MR damper with an internal piston guide, to guarantee the alignment of damper piston and cylinder. This design is preferred because the piston and coil are simpler and can be implemented more easily. The remaining aspects of the design are identical to the damper in Figure 2(c).

The space applications of MR dampers include those provided in [24-28]. As shown in Figure 3, the studies by $\mathrm{Oh}$ et al. provide an analysis of the benefits of a damper placed at the base of the structure in place of one of the truss members, for controlling the structural vibrations $[24,25]$. In other similar studies by Dominguez et al. the use of a MR damper incorporated as one of the truss members is evaluated for controlling vibrations, while the structure is excited in different planes by a shaker, in the manner shown in Figure 4 $[26,27]$. A more recent study proposes replacing one of the truss members with a MR damper [28]. Simulation results in [28] confirm the effectiveness of MR dampers for suppressing vibrations within the structure, even in case of a truss failure. The results in [24-28] show that MR dampers with semiactive control are effective in suppressing vibrations in lightweight and flexible space truss structures. It is important to note that all of these studies recommend replacing one of the truss

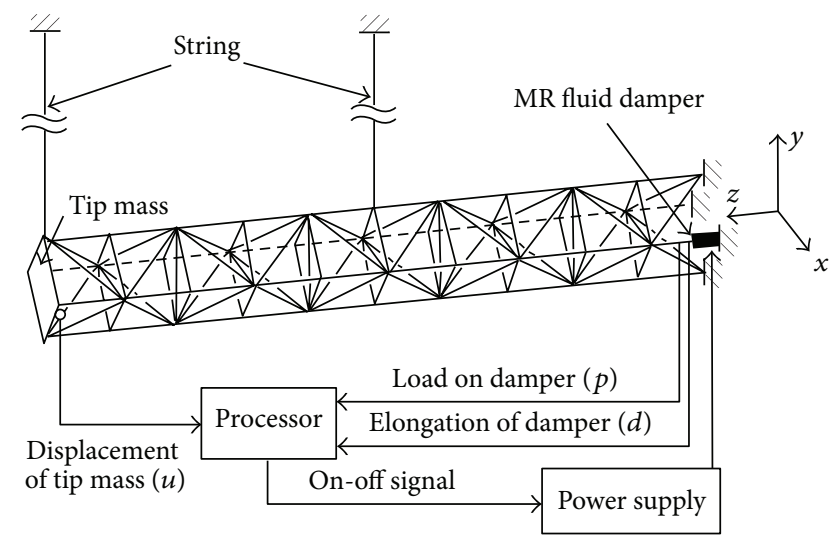

FIGURE 3: The experimental setup for controlling vibrations of a space truss using MR dampers installed at the root of the structure [24].

members with a MR damper, which at times may not be possible or desirable.

Although the studies in [24-28] have documented the efficacy of MR dampers in controlling space structure vibrations, they do not address the added weight to the structure due to the MR damper. As it is well known, one of the critical aspects of any space structure is its weight. The added weight creates both mission challenges with placing the heavier cargo into orbit, as well as the dynamic effects caused by the heavier truss member. MR dampers in Figure 2 can provide large forces and long strokes, but that comes at the expense of a higher weight that for space systems is often the most critical factor. It is not feasible to scale down the damper to the required size simply because the coil leads must go through a super small piston rod, which physically may not be able to accommodate them. This study intends to address this challenge by suggesting a MR damper with a novel structure that can be incorporated into a space structure as a truss member, while maintaining the low weight requirements through incorporating lighter elements and maintaining the MR damper volume to a minimum.

\section{Double-Piston MR Damper Concept}

As shown in Figure 5, the proposed double-piston MR damper has two dynamic seals, in contrast to the single incorporated in monotube dampers. The two dynamic seals are connected by a rigid rod that causes them to have the same motion. The rigid rod also incorporates a coil piston that is placed midway on the rod, as denoted by item 4 in Figure 5 . The volume of the MR fluid chamber remains unchanged as the rod and all of the components rigidly connected to it move back and forth within the damper body, therefore eliminating the need for an accumulator. As the MR fluid flows from one chamber to the opposite side, through the annular orifice (item 10 in Figure 5) it experiences a flow resistance that is proportional to the magnetic flux field within the gap. This results in a damping force that changes directly proportional to the electrical current supplied to the damper. The damper works in a combination of shear and valve mode. The valve 


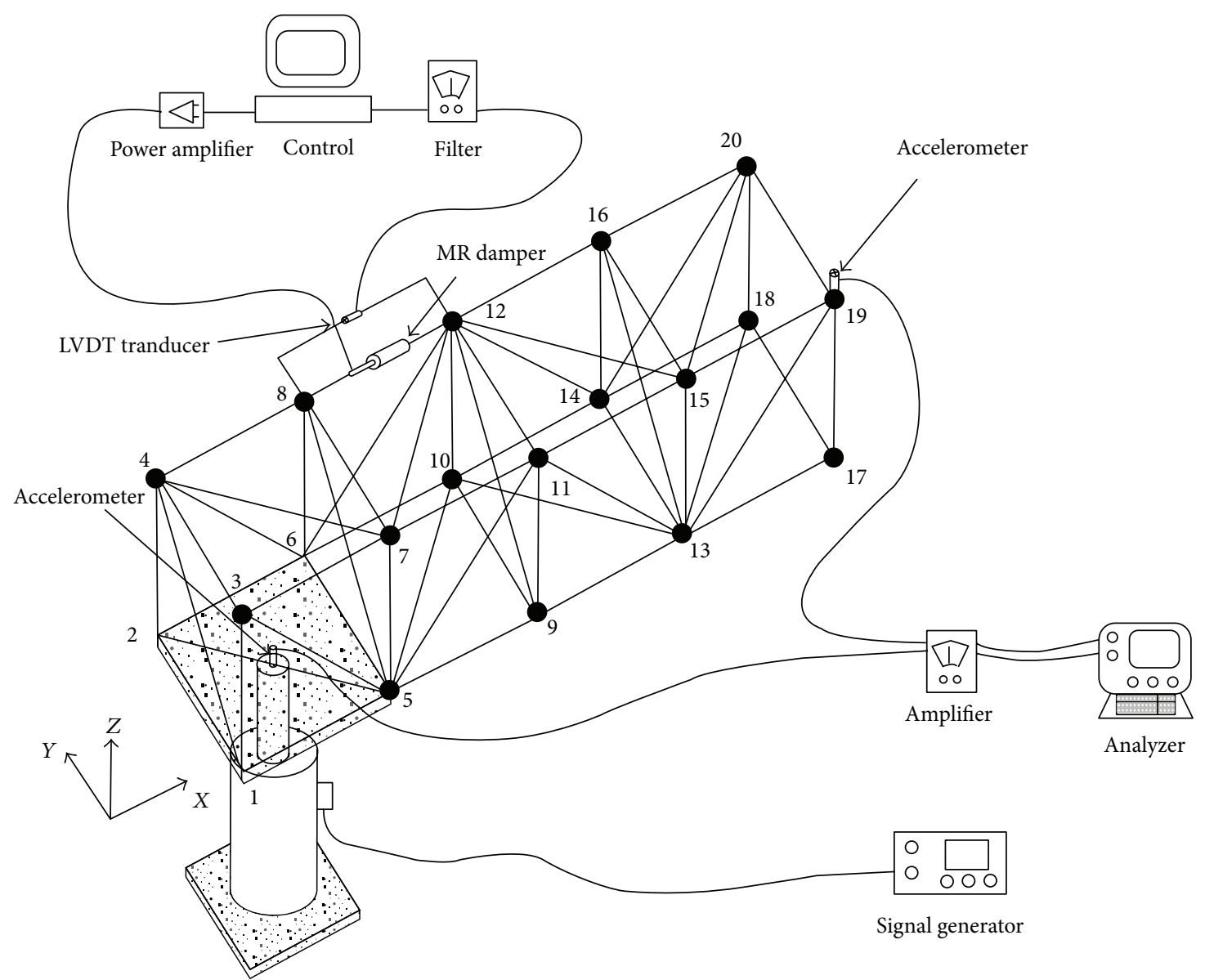

FIGURE 4: Test setup for controlling vibrations in a space truss with MR dampers, while excited by an electromagnetic shaker [26].

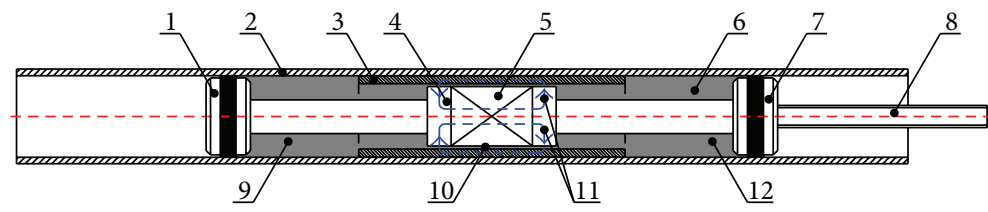
(1) Left seal piston
(7) Right seal piston
(2) Outer tube
(8) Piston rod
(3) Inner tube
(9) Left chamber
(4) Coil piston
(10) Annular orifice
(5) Coil
(11) Magnetic flux path
(6) MR fluid
(12) Right chamber

FIGURE 5: Schematic configuration of the double-piston MR damper.

mode can be controlled by the narrowing of the midsection of the damper and also the outer diameter of the coil piston.

If no magnetic field is applied, the MR damper provides a relatively small damping force, resulting from the viscosity of the MR fluid. With no current supplied to the damper (referred to as "off-state"), the damping force is directly proportional to the fluid viscosity and the MR orifice is designed into the damper, and it cannot be changed in real time. When, however, current is supplied to the damper (referred to as "on-state"), the damping force can be controlled in real time due to the changing yield stress of the MR damper as it passes through the MR orifice. The drag forces from the two dynamic seals are present in both on- and off-states. The seals are designed such that the seal drag forces are much smaller than the total damping force, especially in on-state.

The design shown in Figure 5 allows the use of nonmagnetic materials such as aluminum alloy or even plastic for majority of the damper parts, of course, except for the parts in the magnetic flux path: the inner tube and coil piston. Beyond minimizing the damper weight, it is desirable to 


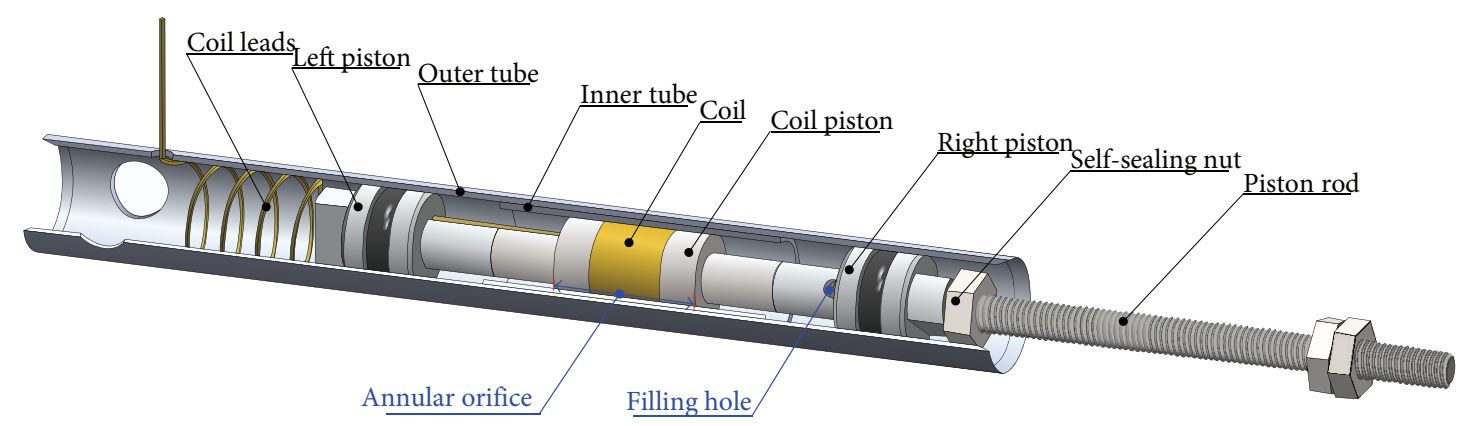

FIGURE 6: MR damper prototype cross-section.
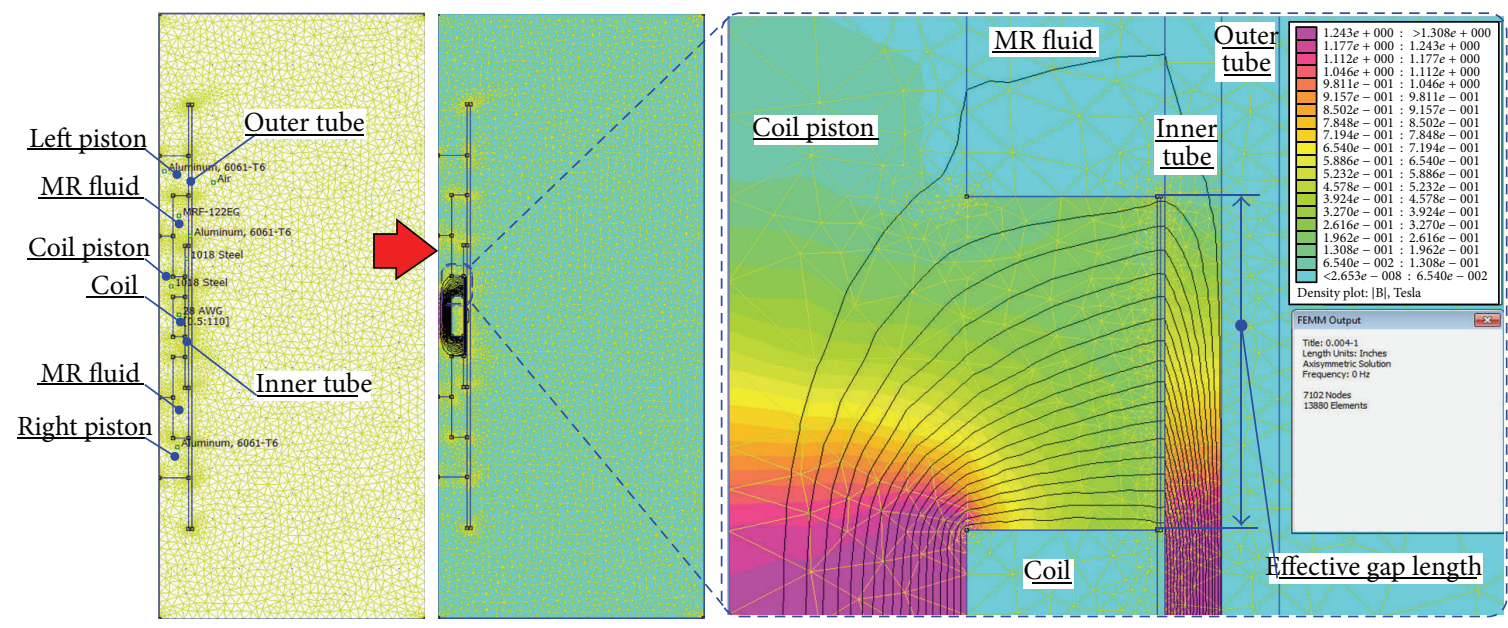

FIGURE 7: Magnetic field analysis of the prototype damper.

include sensors required for control into the design, such as displacement and force sensors. It is also possible to integrate springs inside of the fluid chamber, in order to provide a restoring force that works in parallel to the damping force.

The most unique aspect of the MR damper design described here is its double-piston structure. This feature will not only bring a light self-weight, but also allow the damper to have a small exterior diameter. The damper stroke can be made as long as needed, by making the damper as long as needed for a particular application. The details of the design are further included in Chinese Patent number ZL 201110420869.8 .

\section{Prototype Double-Piston MR Damper}

A prototype damper based on the concept described earlier has been designed and fabricated at the Center for Vehicle Systems and Safety (CVeSS) of Virginia Polytechnic Institute and State University (Virginia Tech). The prototype's crosssection is shown in Figure 6.

The outer tube and seal pistons that house the dynamic seals are made of 6000 series aluminum. The coil piston and inner tube are made of 12L14 steal. The outer tube is slightly heated before inserting the inner tube into it. The coil is wrapped on a lathe at very low speeds and the leads are passed through the one side (in our case, the left piston) to the outside. The damper is filled with MRF-122EG fluid from Lord Corporation, through the filling hole in right piston denoted in Figure 6. A self-sealing nut is used to lock the rod and piston in place and reduce the likelihood of fluid leakage.

An important aspect of MR dampers is the design of the electromagnet, in terms of ensuring that the magnetic circuit does not reach saturation at higher electrical currents. Ideally one would aim for a nearly uniform magnetic flux density throughout the entire circuit. For the design in Figures 6, a commercially available software called FEMM was used for analyzing the distribution of the flux field density, as shown in Figure 7, and shows the model of the prototype damper and magnetic field density distribution in annular orifice for a 0.5 Amp electric current passing through the coil, which includes 110 turns of 28 AWG coil wire. The zoomed in area within the flow gap shows that the flux lines are perpendicular to the fluid flow. The diagram further shows little leakage between the edges of the coil piston and the inner tube.

Figure 8 shows the average flux density along the effective gap for various electrical currents and gap sizes. As the gap size increases, the average magnetic flux density decreases due to an increase in the magnetic field reluctance, with a slow trend. The relationship between average magnetic flux density and gap size is approximately linear, as shown in Figure 8(b). Figure 8(c) shows that the average magnetic flux density increases as electrical current increases for a given 


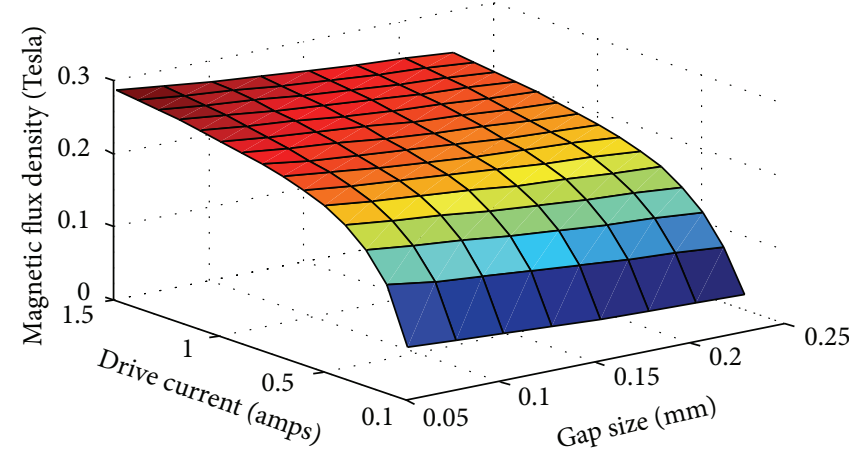

(a)

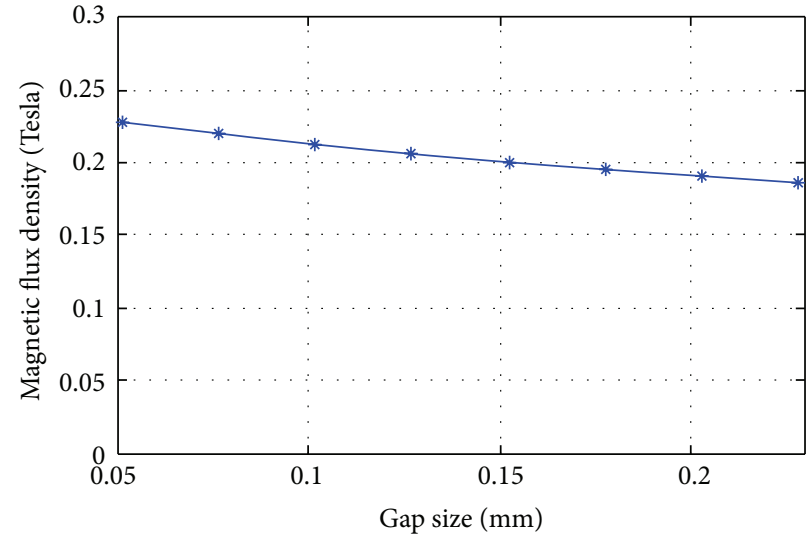

$\rightarrow$ Drive current: $0.5 \mathrm{amps}$

(b)

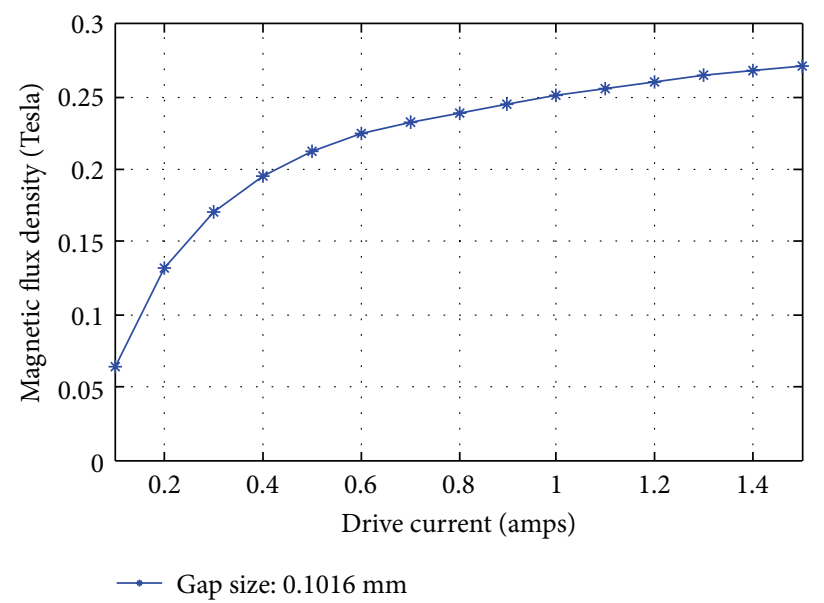

(c)

Figure 8: Average magnetic flux density along the effective gap length: (a) various drive currents (from 0.1 amps to 1.5 amps) and various gap sizes (from $0.05 \mathrm{~mm}$ to $0.23 \mathrm{~mm}$ ), (b) various gap sizes with drive current $0.5 \mathrm{amps}$, and (c) various drive currents with gap size $0.1016 \mathrm{~mm}$ (0.004 in).

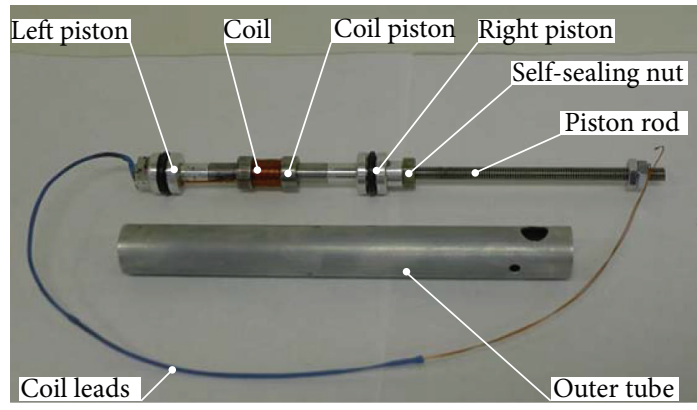

(a)

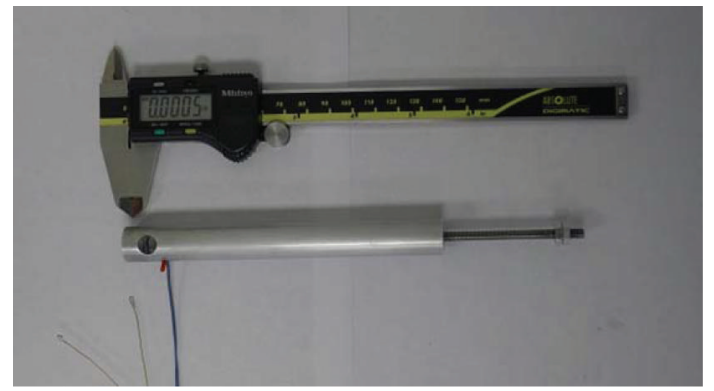

(b)

FIGURE 9: The fabricated prototype damper: (a) parts and (b) assembly.

gap size, with a nonlinear trend that reaches a plateau at higher currents. The plateau is caused by the saturation of the magnetic field at higher currents.

The technical specifications for the prototype design are given in Table 1. The weight of the fabricated prototype damper, shown in Figure 9, is only $82 \mathrm{~g}$, and the outside diameter of the damper is $16 \mathrm{~mm}$. This design is far lighter than earlier designs that we are aware of.

Another excellent feature of the double-piston MR damper is its simple appearance. The damper is compact and 


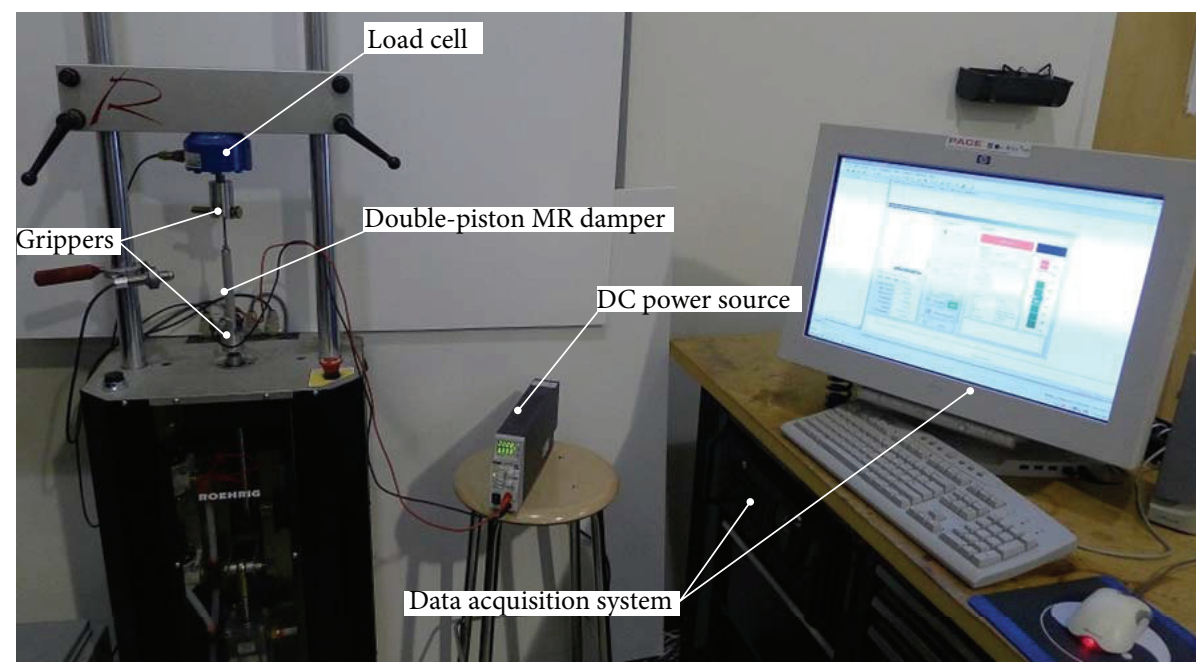

FIGURE 10: Experimental setup for the prototype damper.

TABLE 1: Technical specifications of the prototype damper.

\begin{tabular}{|c|c|c|}
\hline Parameters & Value (metric) & Value (imperial) \\
\hline \multicolumn{3}{|l|}{ MRF-122EG } \\
\hline Viscosity@40C & $0.042 \pm 0.020 \mathrm{~Pa}-\mathrm{s}$ & - \\
\hline Density & $2.28-2.48 \mathrm{~g} / \mathrm{cm}^{3}$ & - \\
\hline Operating temperature & -40 to $+130^{\circ} \mathrm{C}$ & - \\
\hline \multicolumn{3}{|l|}{ Outer tube } \\
\hline Outer diameter & $15.875 \mathrm{~mm}$ & $5 / 8$ in \\
\hline Inner diameter & $14.224 \mathrm{~mm}$ & 0.560 in \\
\hline Total length & $139.7 \mathrm{~mm}$ & $5.50 \mathrm{in}$ \\
\hline \multicolumn{3}{|l|}{ Inner tube } \\
\hline Outer diameter & $14.224 \mathrm{~mm}$ & $0.560 \mathrm{in}$ \\
\hline Inner diameter & $12.573 \mathrm{~mm}$ & 0.495 in \\
\hline Total length & $35.56 \mathrm{~mm}$ & 1.40 in \\
\hline \multicolumn{3}{|l|}{ Coil piston } \\
\hline Outer diameter & $12.370 \mathrm{~mm}$ & $0.487 \mathrm{in}$ \\
\hline Lip width & $5.08 \mathrm{~mm}$ & $0.20 \mathrm{in}$ \\
\hline Total length & $20.32 \mathrm{~mm}$ & 0.80 in \\
\hline \multicolumn{3}{|l|}{ Gap } \\
\hline Gap size & $0.1016 \mathrm{~mm}$ & 0.004 in \\
\hline Effective gap length & $10.16 \mathrm{~mm}$ & 0.40 in \\
\hline \multicolumn{3}{|l|}{ Coil } \\
\hline Core diameter & $6.858 \mathrm{~mm}$ & $0.270 \mathrm{in}$ \\
\hline Length & $10.16 \mathrm{~mm}$ & $0.40 \mathrm{in}$ \\
\hline Wire gauge & - & 28 \\
\hline Number of turns & 110 & 110 \\
\hline Maximum stroke & $15.24 \mathrm{~mm}$ & 0.60 in \\
\hline Weight & $82 \mathrm{~g}$ & $2.9 \mathrm{oz}$ \\
\hline
\end{tabular}

includes no outside passages, which is helpful for packaging and folding and unfolding of space structures. Additionally, the damper can be designed in various lengths to accommodate the size necessary for a given structure.

\section{Experimental Setup}

The electromagnetic actuated (EMA) damper dynamometer is used for testing the prototype damper. As shown in

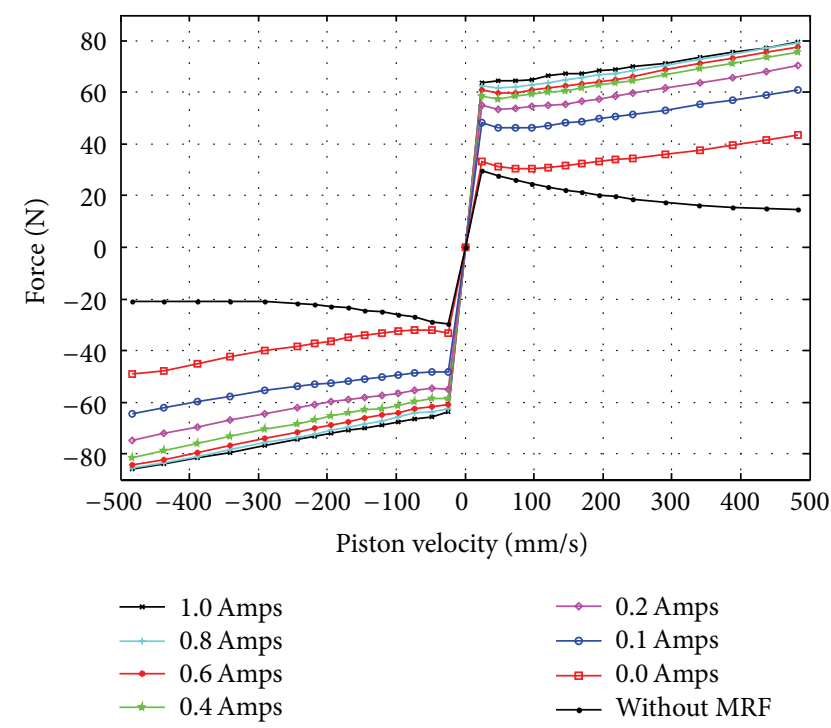

FIGURE 11: The prototype damper quasisteady tested force versus velocity curves.

Figure 10, the damper is mounted vertically in the test rig between a stationary head at the top and a moving actuator at the bottom. The tests are performed at a fixed amplitude at various frequencies, resulting in different peak-to-peak velocities. The resulting damper forces are measured by a load cell at the stationary head. A DC power supply is used to change the driving current to the damper. The experiments are carried out at room temperature, approximately 25 degrees Celsius (77 degrees Fahrenheit).

\section{Test Results}

The test results are shown in Figures 11 and 12. The damper is tested at various relative displacements and velocities (as described earlier) and with different currents supplied to the damper. Figure 11 shows the peak forces versus peak 


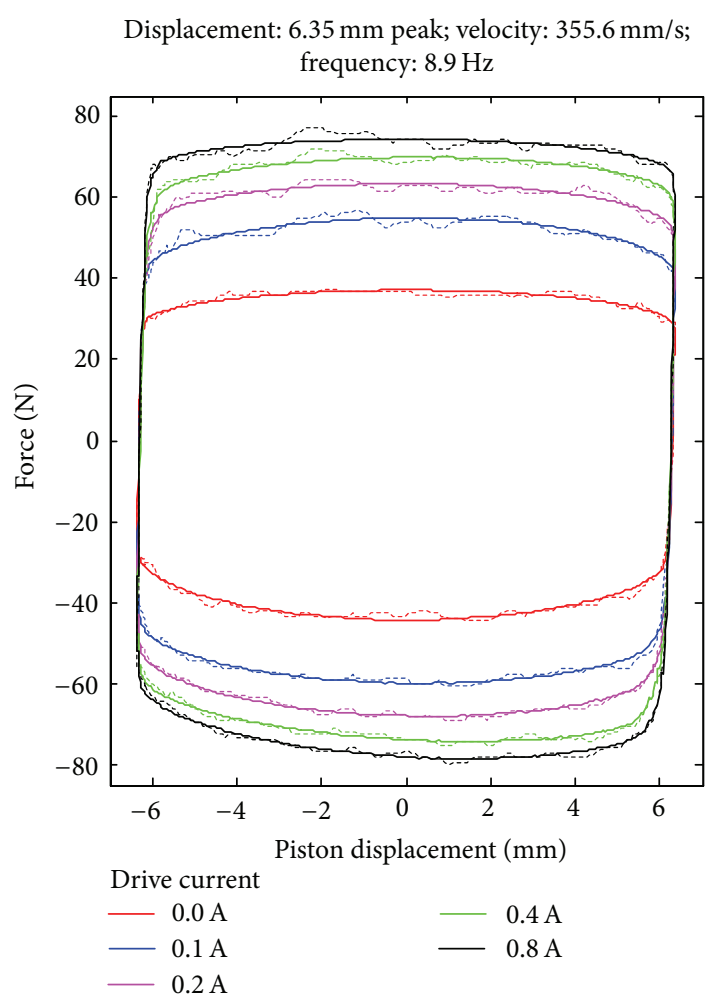

(a)

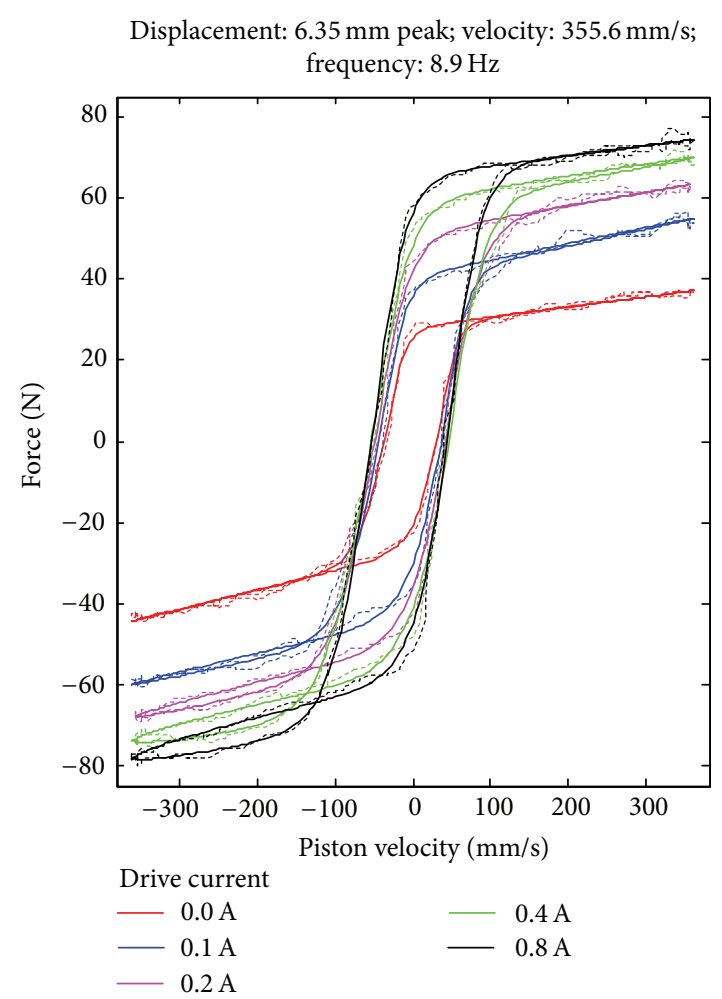

(b)

Figure 12: Hysteresis curves comparison at different drive current. Tested data (- - ) and reconstructed results from identified parameters (-): (a) force versus displacement hysteresis curves and (b) force versus velocity hysteresis curves.

velocities, for each of the 7 currents supplied to the damper. The figure also shows the damping force when the damper is empty, in order to measure seal drag. A comparison of the damping force for no current and empty conditions indicate that seal drag contributes significantly to the damping force at lower velocities and lower currents. At higher velocities and when higher currents are applied to the damper, the effect of the seal drag is far less. The results in Figure 11 also show the viscous effect of the MR fluid versus the rheological changes resulting from magnetic field. The damping force at $0.0 \mathrm{Amp}$ is due to the viscous effect of the fluid. Comparing this force with others at higher currents indicates the classical trend that is often observed for MR dampers. The damping force at lower currents is dominated by the fluid viscosity, while at higher currents it plays a less significant role. Figure 11 also shows that the change in damping force at higher currents becomes less as the damper starts to saturate, a phenomenon that was discussed earlier. The ratio between the maximum damping at $1.0 \mathrm{Amp}$ and the minimum damping at $0.0 \mathrm{Amp}$ is approximately $2: 1$. Although this ratio is smaller than some of the larger MR damper designs, it is quite expected for a compact design such as what is described in this study. The damping forces shown in Figure 11 indicate that the damper can satisfactorily damp out the dynamics of a relatively large size space truss structure, which will be the topic of a future study.
Figure 12 shows the damping performance for a complete cycle, for a sinusoidal input at $6.35 \mathrm{~mm}$ at $8.9 \mathrm{~Hz}$, resulting in a peak velocity of $355.6 \mathrm{~mm} / \mathrm{sec}$. The dashed lines are the tested data, whereas the solid lines that closely trace the test data are from a damper model that will be described later. Figure 12(a) shows force versus displacement, which indicates the amount of work performed by the damper. Figure 12(b) shows force versus velocity, which is a measure of the energy dissipated by the damper. The results are plotted for various currents, ranging from 0.0 to 0.8 . Figure 12 (a) shows that the work performed by the damper increases with increasing current, initially at a faster rate and eventually at a slower rate. This trend is also observed in damping forces shown in Figure 12(a) and peak damping forces discussed earlier in Figure 11. Additionally, Figure 12(b) shows the hysteresis, which increases with increasing current. The flatten portion of the hysteresis loops indicate that the damper is operating in the postyield region of the fluid, with the bend in each curve signifying the transition from pre- to postyield region. One last observation is that the damper exhibits a local hysteresis in compression at higher currents. This is most likely causes by the shear characteristics of the MR fluid within the gap at higher shear strain rates. The same hysteresis is not observed in rebound. The damping characteristics in Figure 12 are in line with what is commonly observed in MR dampers. 


\section{Asymmetric Model}

Various parametric models have been developed in the past for modeling the hysteretic characteristics of MR dampers [29]. Parametric models usually assume that the MR damper has a symmetric damper force response during one test cycle. The differences between the compression and rebound stroke are ignored. A nonsymmetric Bouc-Wen model is suggested for dealing with the asymmetric damper force [30]. The method uses a hysteresis variable that is a function of the relative velocity across the damper. The asymmetry in this research occurs in the preyield to postyield transform region. Another asymmetric damping force generation (ADFG) algorithm is employed to generate the asymmetric damping force in compression and rebound from a symmetric MR damper design [31]. The generalized model in [31] can be used to characterize both the symmetric and asymmetric hysteresis characteristics of the damper at various damper velocities, including force asymmetry occurring in the preyield region. Because the hysteresis occurs in both pre- and postyield regions, an alternative model is needed for the damper force in Figure 12(b).

The hyperbolic tangent model that is often used to model the hysteresis characteristics is modified for the purpose of this study $[32,33]$. The modified model is given by

$$
\begin{aligned}
f= & \left(c+c^{\prime} \operatorname{sign}(f)\right) \dot{x}+\left(k+k^{\prime} \operatorname{sign}(f)\right) x \\
& +\alpha(\tanh (\beta \dot{x}+\delta \operatorname{sign}(x)))+\left(f_{0}+f_{0}^{\prime} \operatorname{sign}(f)\right),
\end{aligned}
$$

where $c$ and $k$ are the viscous and stiffness coefficients, $\alpha$ is the scale factor of the hysteresis, $\beta$ and $\delta$ are the hysteresis variables given by the hyperbolic tangent function, and $f_{0}$ is the damper force offset. $c^{\prime}, k^{\prime}$, and $f_{0}^{\prime}$ are the modification parameters, respectively.

To ensure that the force versus displacement and force versus velocity curves transition smoothly at the force zero crossing, an additional constraint is imposed on the three variables, in which

$$
c^{\prime} \dot{x}_{0}+k^{\prime} x_{0}+f_{0}^{\prime}=0,
$$

where $\dot{x}_{0}$ and $x_{0}$ are the velocity and displacement when the force crosses zero.

The asymmetric hyperbolic tangent model includes nine parameters, that is, $c, c^{\prime}, k, k^{\prime}, \alpha, \beta, \delta, f_{0}$, and $f_{0}^{\prime}$. But it only contains a simple hyperbolic tangent function and is computationally efficient in the context of parameter identification. The model uses the piston displacement and velocity as input and calculates the damper force given by (1) and (2). The nine parameters are identified offline using a nonlinear least square algorithm within the MATLAB's Optimization Toolbox.

The identified parameters are shown in Table 2. Using the parameters estimated from the system identification process, the force versus piston displacement and velocity was reconstructed and compared with the experimental data curves. In Figures 12(a) and 12(b), the solid lines that closely trace the tested data (in dashed line) are from the model. The
TABLE 2: Identified model parameters.

\begin{tabular}{lccccc}
\hline \multirow{2}{*}{ Parameters } & \multicolumn{5}{c}{ Drive currents (A) } \\
& $0.0 \mathrm{~A}$ & $0.1 \mathrm{~A}$ & $0.2 \mathrm{~A}$ & $0.4 \mathrm{~A}$ & $0.8 \mathrm{~A}$ \\
\hline$c$ & 0.0364 & 0.0421 & 0.0394 & 0.0350 & 0.0338 \\
$c^{\prime}$ & 0.0113 & 0.0012 & 0.0058 & 0.0030 & 0.0095 \\
$k$ & -0.0020 & -0.0413 & -0.1307 & -0.2078 & -0.3055 \\
$k^{\prime}$ & -0.0105 & -0.1021 & -0.1167 & -0.3276 & -0.2784 \\
$\alpha$ & 27.8907 & 42.8064 & 52.0225 & 59.4834 & 64.1797 \\
$\beta$ & 0.0363 & 0.0273 & 0.0218 & 0.0201 & 0.0230 \\
$\delta$ & 1.2543 & 1.1297 & 1.0351 & 1.0398 & 1.1648 \\
$f_{0}$ & -2.7646 & -3.6630 & -4.0278 & -3.5516 & -6.4937 \\
$f_{0}^{\prime}$ & -0.2350 & -0.4395 & -0.4275 & -0.1157 & -0.0181 \\
\hline
\end{tabular}

comparison indicates that both the damper force slope and local hysteresis loop are represented accurately by the new model.

\section{Conclusions}

The design, fabrication, and testing of a new double-piston MR damper for space applications was discussed. The design concept for the damper was described in detail, along with an overview of MR dampers for industrial and space applications. The fabrication of the MR damper and the details of the analysis of the electromagnetic aspects of the damper using a commercially available software called FEMM was also described. It was shown that it is possible to design the damper such that it meets the weight and size requirements for being included in a space truss structure, as one of the truss members. The FEMM analysis showed that the design of the coil and the remainder of the electromagnetic circuit are balanced in terms of the magnetic flux density, which the model estimates to be approximately 0.25 Tesla at the maximum current of $1.0 \mathrm{Amp}$. The prototype design is tested in a damper dynamometer, using sinusoidal input at various amplitudes and frequencies. The test results show that the damper can provide nearly $80 \mathrm{~N}$ of damping force at its maximum velocity and current. The ratio between maximum damping at $1.0 \mathrm{Amp}$ and minimum damping at $0.0 \mathrm{Amp}$ is $2: 1$, which is believed to be sufficient for space applications, although it is smaller than the MR dampers that are used for automotive applications. The test results also showed that the seal drag could contribute significantly to the damping forces, particularly at lower electrical currents.

Evaluating the test results for a complete cycle that corresponds to damper velocity of $355.6 \mathrm{~mm} / \mathrm{sec}$ (Amplitude: $6.35 \mathrm{~mm}$, frequency: $8.9 \mathrm{~Hz}$ ) shows that the damper behaves similar to its larger counterparts in terms of damper force rise in pre- and postyield regions of the fluid, saturation at higher currents, and hysteresis characteristics. Evaluating damper force versus displacement shows no cavitation of the damper. The plots follow the classical rectangular shapes, with the area under the curve representing the work performed by the damper. The work by the damper initially increases rapidly with increasing current and tapers off at higher currents as the damper starts to saturate. The same characteristics are 
observed in damper force versus velocity plots. The latter plots also show the hysteresis of the damper, in both pre- and postyield regions.

A model that takes advantage of the models proposed for MR dampers in earlier studies was proposed. The model, which uses a hyperbolic tangent function includes a number of coefficients that are found based on the damper test results. The model is intended to represent the force-displacement and force-velocity characteristics of the damper, as well as the asymmetric forces observed in test results. A comparison of the modeling results and test data indicated that the model accurately represents the force characteristic of the damper.

Beyond this study that described the successful design, fabrication, and testing of the MR damper, the authors intend to use the damper in a space structure and report on the effects of the damper in reducing structural vibrations in a future study.

\section{Conflict of Interests}

The authors declare that there is no conflict of interests regarding the publication of this paper.

\section{Acknowledgments}

The first author expresses his gratitude to China Scholarship Council (CSC). Financial support from CSC brought the opportunity for the first author to work in the Center for Vehicle Systems and Safety (CVeSS) at Virginia Polytechnic Institute and State University. This research was also financially supported by the National Natural Science Foundation of China (Grant nos. 10972065 and 11372083). Thanks are also extended to Michael Craft and Clément Nagode, for their valuable assistance during the prototype damper testing.

\section{References}

[1] H. Lee and S. Choi, "Control and response characteristics of a magneto-rheological fluid damper for passenger vehicles," Journal of Intelligent Material Systems and Structures, vol. 11, no. 1, pp. 80-87, 2000.

[2] M. Ahmadian and C. A. Pare, "A quarter-car experimental analysis of alternative semiactive control methods," Journal of Intelligent Material Systems and Structures, vol. 11, no. 8, pp. 604-612, 2000.

[3] G. Z. Yao, F. F. Yap, G. Chen, W. H. Li, and S. H. Yeo, "MR damper and its application for semi-active control of vehicle suspension system," Mechatronics, vol. 12, no. 7, pp. 963-973, 2002.

[4] H. Du, K. Y. Sze, and J. Lam, "Semi-active $H_{\infty}$ control of vehicle suspension with magneto-rheological dampers," Journal of Sound and Vibration, vol. 283, no. 3-5, pp. 981-996, 2005.

[5] W. H. Liao and D. H. Wang, "Semiactive vibration control of train suspension systems via magnetorheological dampers," Journal of Intelligent Material Systems and Structures, vol. 14, no. 3, pp. 161-172, 2003.

[6] Y. K. Lau and W. H. Liao, "Design and analysis of magnetorheological dampers for train suspension," Proceedings of the Institution of Mechanical Engineers F: Journal of Rail and Rapid Transit, vol. 219, no. 4, pp. 261-276, 2005.
[7] Y. T. Choi and N. M. Wereley, "Vibration control of a landing gear system featuring electrorheological/magnetorheological fluids," Journal of Aircraft, vol. 40, no. 3, pp. 432-439, 2003.

[8] D. C. Batterbee, N. D. Sims, R. Stanway, and Z. Wolejsza, "Magnetorheological landing gear. 1: a design methodology," Smart Materials and Structures, vol. 16, no. 6, pp. 2429-2440, 2007.

[9] D. C. Batterbee, N. D. Sims, R. Stanway, and M. Rennison, "Magnetorheological landing gear: 2. Validation using experimental data," Smart Materials and Structures, vol. 16, no. 6, pp. 24412452, 2007

[10] S. Marathe, F. Gandhi, and K. W. Wang, "Helicopter blade response and aeromechanical stability with a magnetorheological fluid based lag damper," Journal of Intelligent Material Systems and Structures, vol. 9, no. 4, pp. 272-282, 1998.

[11] G. M. Kamath, N. M. Wereley, and M. R. Jolly, "Characterization of magnetorheological helicopter lag dampers," Journal of the American Helicopter Society, vol. 44, no. 3, pp. 234-248, 1999.

[12] W. Hu, N. M. Wereley, L. Chemouni, and P. C. Chen, "Semiactive linear stroke magnetorheological fluid-elastic helicopter lag damper," Journal of Guidance, Control, and Dynamics, vol. 30, no. 2, pp. 565-575, 2007.

[13] W. Hu and N. M. Wereley, "Hybrid magnetorheological fluidelastomeric lag dampers for helicopter stability augmentation," Smart Materials and Structures, vol. 17, no. 4, Article ID 045021, 2008.

[14] Y. T. Choi and N. M. Wereley, "Biodynamic response mitigation to shock loads using magnetorheological helicopter crew seat suspensions," Journal of Aircraft, vol. 42, no. 5, pp. 1288-1295, 2005.

[15] G. J. Hiemenz, W. Hu, and N. M. Wereley, "Semi-active magnetorheological helicopter crew seat suspension for vibration isolation," Journal of Aircraft, vol. 45, no. 3, pp. 945-953, 2008.

[16] S. J. Dyke, B. F. Spencer Jr., M. K. Sain, and J. D. Carlson, "Modeling and control of magnetorheological dampers for seismic response reduction," Smart Materials and Structures, vol. 5, no. 5, pp. 565-575, 1996 .

[17] S. J. Dyke, B. F. Spencer Jr., M. K. Sain, and J. D. Carlson, "An experimental study of MR dampers for seismic protection," Smart Materials and Structures, vol. 7, no. 5, pp. 693-703, 1998.

[18] G. Yang, B. F. Spencer Jr., J. D. Carlson, and M. K. Sain, "Largescale MR fluid dampers: modeling and dynamic performance considerations," Engineering Structures, vol. 24, no. 3, pp. 309323, 2002.

[19] Q. Sun, L. Zang, J. Zhou, and Q. Shi, "Experimental study of the semi-active control of building structures using the shaking table," Earthquake Engineering and Structural Dynamics, vol. 32, no. 15, pp. 2353-2376, 2003.

[20] A. Rodríguez, F. Pozo, A. Bahar, L. Acho, Y. Vidal, and J. Rodellar, "Force-derivative feedback semi-active control of base-isolated buildings using large-scale MR fluid dampers," Structural Control \& Health Monitoring, vol. 19, no. 1, pp. 120145, 2012.

[21] M. Ahmadian and J. C. Poynor, "An evaluation of magneto rheological dampers for controlling gun recoil dynamics," Shock and Vibration, vol. 8, no. 3-4, pp. 147-155, 2001.

[22] H. Hu, X. Jiang, J. Wang, and Y. Li, "Design, modeling, and controlling of a large-scale magnetorheological shock absorber under high impact load," Journal of Intelligent Material Systems and Structures, vol. 23, no. 6, pp. 635-645, 2012. 
[23] Z. C. Li and J. Wang, "A gun recoil system employing a magnetorheological fluid damper," Smart Materials and Structures, vol. 21, no. 10, Article ID 105003, 2012.

[24] H. U. Oh and J. Onoda, "An experimental study of a semiactive magneto-rheological fluid variable damper for vibration suppression of truss structures," Smart Materials and Structures, vol. 11, no. 1, pp. 156-162, 2002.

[25] H. U. Oh, "Experimental demonstration of an improved magneto-rheological fluid damper for suppression of vibration of a space flexible structure," Smart Materials and Structures, vol. 13, no. 5, pp. 1238-1244, 2004.

[26] A. Dominguez, R. Sedaghati, and I. Stiharu, "Semi-active vibration control of adaptive structures using magnetorheological dampers," AIAA Journal, vol. 44, no. 7, pp. 1563-1571, 2006.

[27] A. Dominguez, R. Sedaghati, and I. Stiharu, "Modeling and application of MR dampers in semi-adaptive structures," Computers \& Structures, vol. 86, no. 3-5, pp. 407-415, 2008.

[28] L. S. Huo, G. B. Song, S. Nagarajaiah, and H. Li, "Semi-active vibration suppression of a space truss structure using a fault tolerant controller," Journal of Vibration and Control, vol. 18, no. 10, pp. 1436-1453, 2012.

[29] D. H. Wang and W. H. Liao, "Magnetorheological fluid dampers: a review of parametric modelling," Smart Materials and Structures, vol. 20, no. 2, Article ID 023001, 2011.

[30] N. M. Kwok, Q. P. Ha, M. T. Nguyen, J. Li, and B. Samali, "BoucWen model parameter identification for a MR fluid damper using computationally efficient GA," ISA Transactions, vol. 46, no. 2, pp. 167-179, 2007.

[31] E. R. Wang, W. J. Wang, H. Wang, R. Subhash, and C. Y. $\mathrm{Su}$, "Describing asymmetric hysteretic F-V characteristics of a MR damper resulted form symmetric MR damper," Journal of Nanjing Normal University, vol. 8, no. 1, pp. 1-6, 2008.

[32] N. M. Kwok, Q. P. Ha, T. H. Nguyen, J. Li, and B. Samali, "A novel hysteretic model for magnetorheological fluid dampers and parameter identification using particle swarm optimization," Sensors and Actuators A: Physical, vol. 132, no. 2, pp. 441-451, 2006.

[33] I. Şahin, T. Engin, and Ş. Çemeci, "Comparison of some existing parametric models for magnetorheological fluid dampers," Smart Materials and Structures, vol. 19, no. 3, Article ID 035012, 2010. 

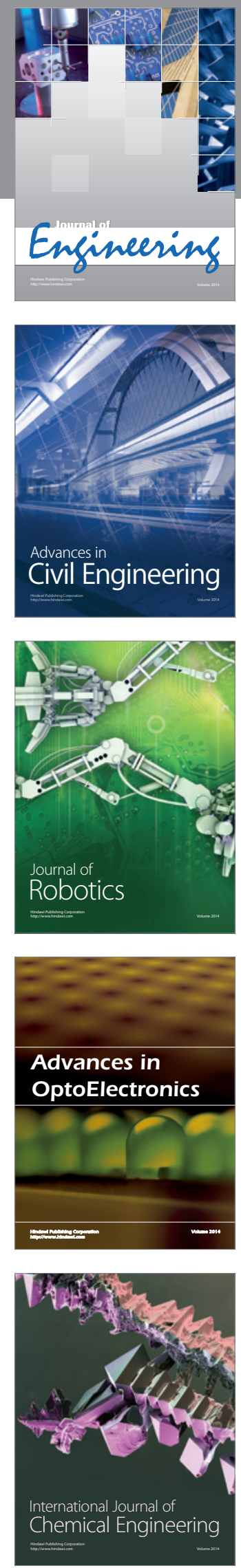

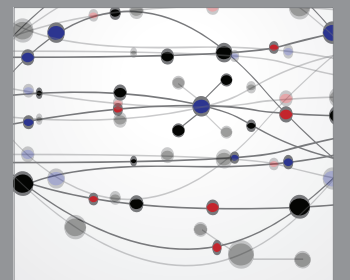

The Scientific World Journal
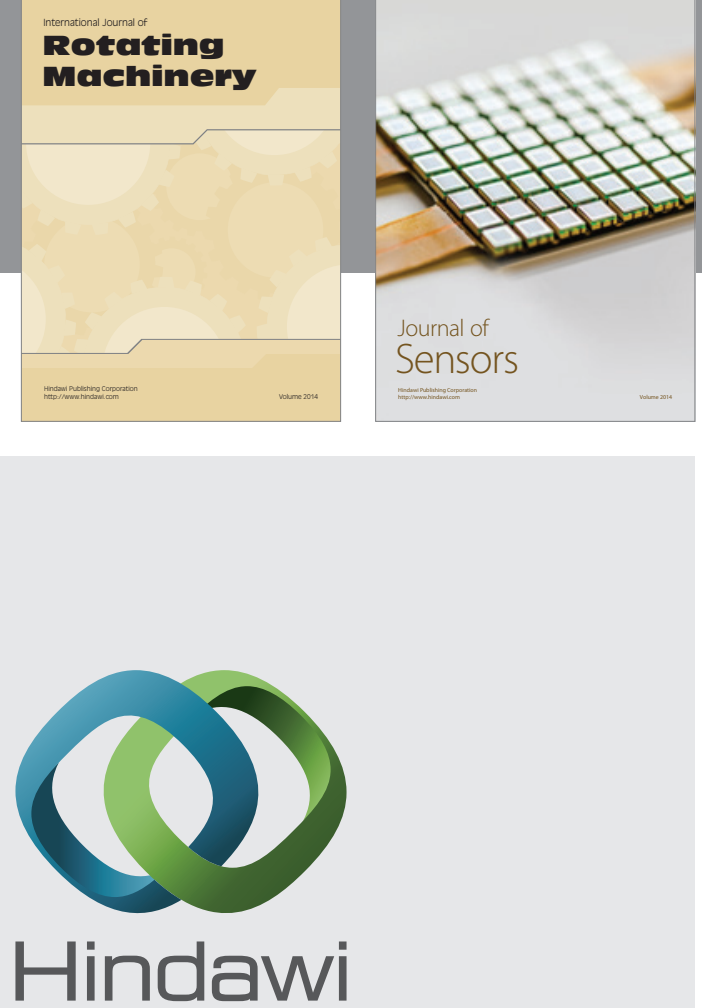

Submit your manuscripts at http://www.hindawi.com
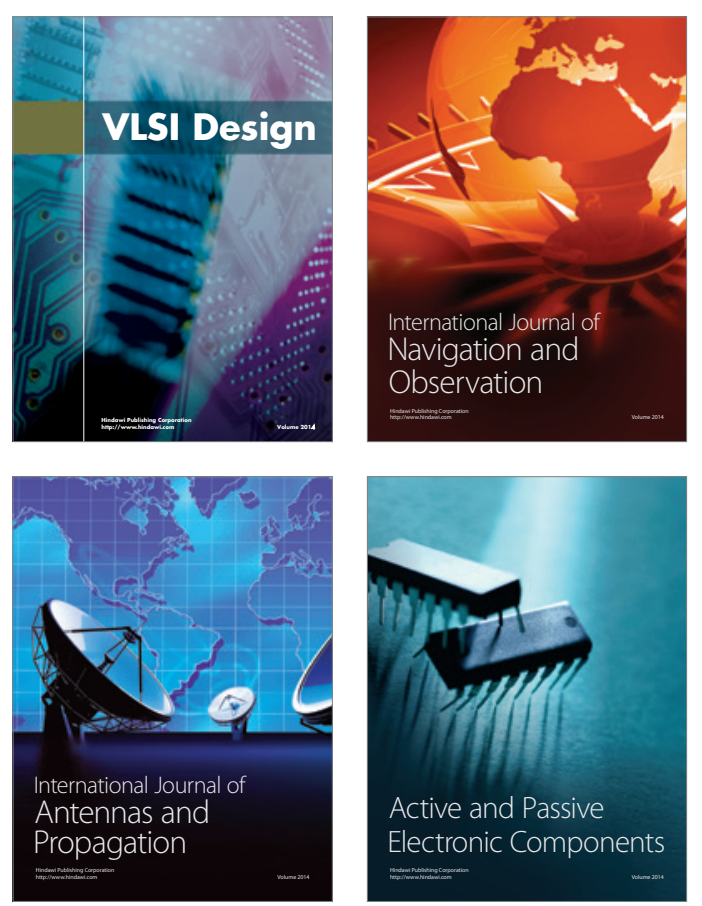
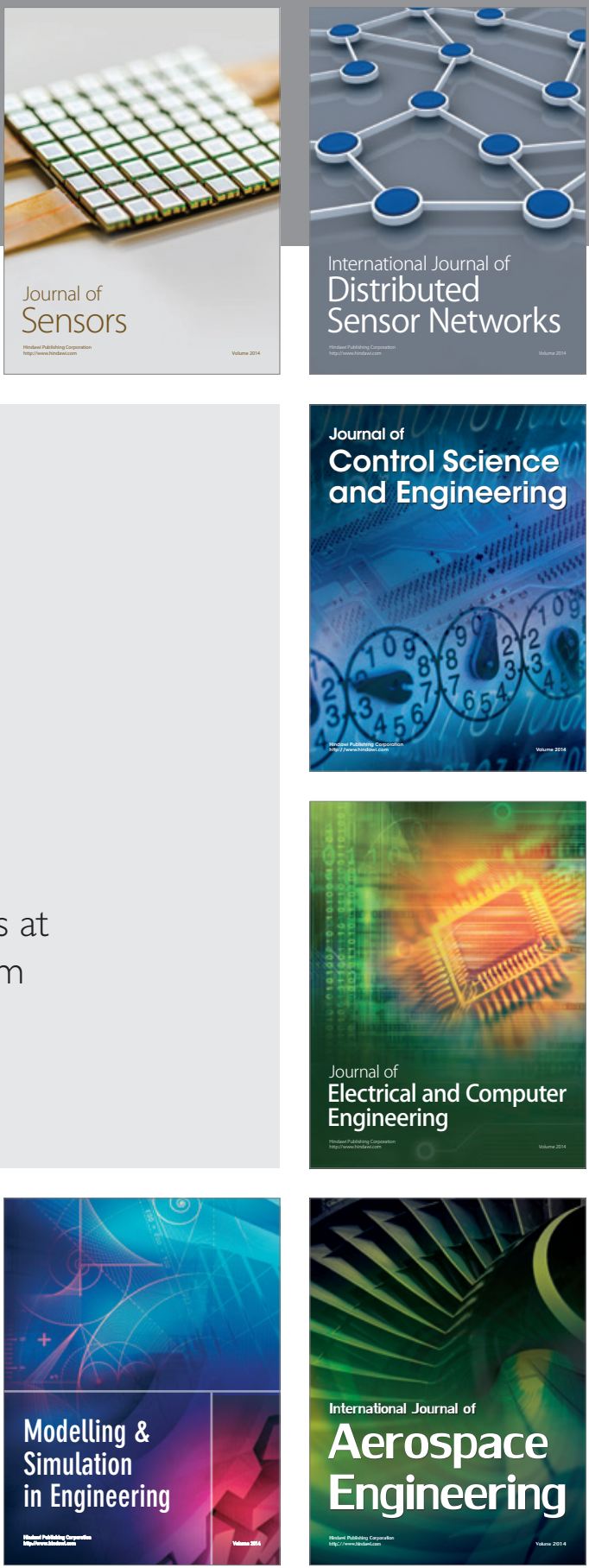

Journal of

Control Science

and Engineering
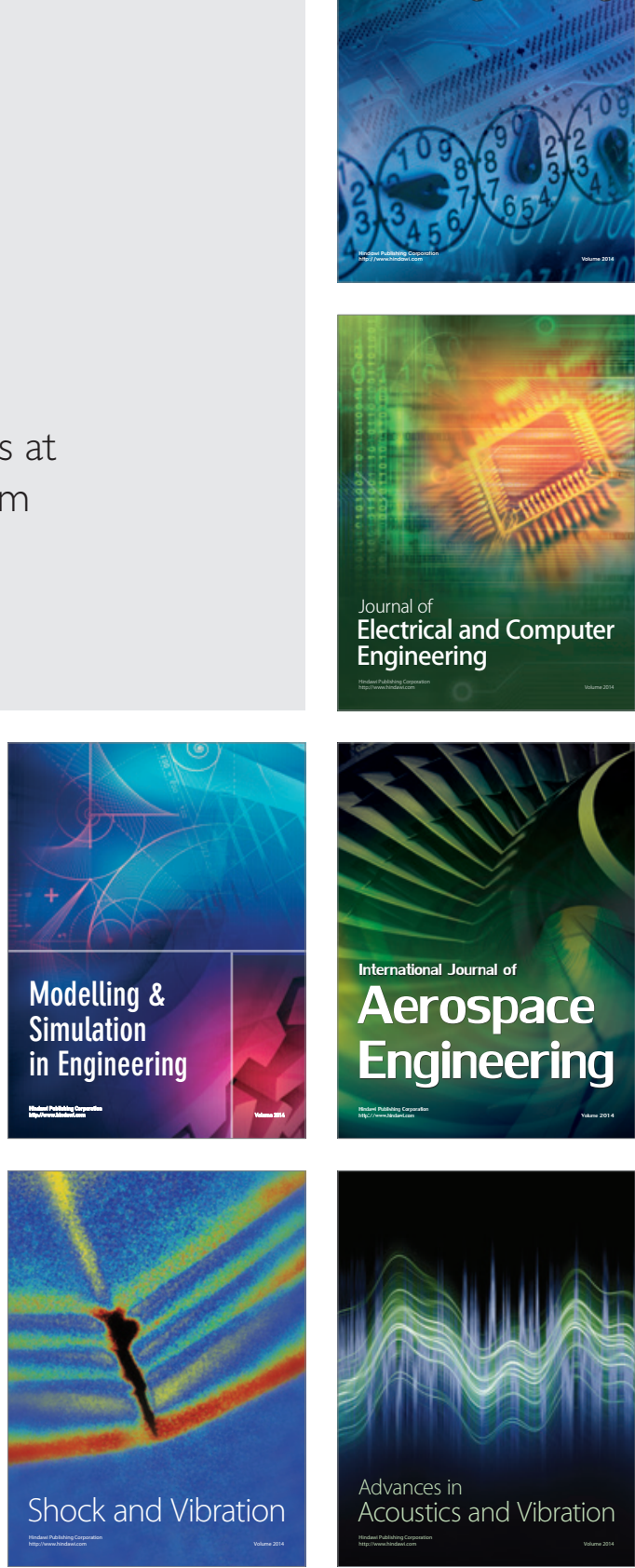